\title{
Application of Microsurgery in Facial Trauma Reconstruction
}

\section{Li-Ren Chang, Seng-Feng Jeng*}

Department of Plastic and Reconstructive Surgery, E-Da Hospital, Kaohsiung, Chinese Taipei.

Email: *jengfamily@hotmail.com

Received April 10 ${ }^{\text {th }}, 2012$; revised May $4^{\text {th }}, 2012$; accepted June $7^{\text {th }}, 2012$

\begin{abstract}
This article is to review the role of microsurgery in facial trauma reconstruction. Microsurgery was developed since 1960s and had been applied on facial trauma from 1970s to treat amputated scalp, nose, ear and lip. Microsurgical replantation of scalp and small parts of face restores function and achieves aesthetic results, but small size of vessels and venous drainage problems are most technical challenging. In this article, we reviewed many talented authors' work to solve those problems in facial tissue replantation. If defects are huge, we need microsurgical free flaps for reconstruction. The current workhorse is anterolateral thigh flap and we reviewed the versatility and new concepts of the flap. Development of perforator flaps was another milestone of flap reconstruction because of better cosmetic result and lower donor site morbidity. We reviewed the concepts, history and application of perforator flaps. Finally, facial replantation developed in recent 5 years to treat extremely large facial defects which cannot be reconstructed with microsurgical flaps and traditional flaps alone. The task is complex and needs a large team to support the whole procedure. We also reviewed the facial allotransplantation, which is the ultimate application of microsurgery in facial trauma reconstruction.
\end{abstract}

Keywords: Microsurgery; Amputation; Facial Trauma; Free Flap; Perforator Flap; Facial Transplantation; Anterolateral Thigh Flap

\section{Introduction}

Trauma, tumor, cancer ablation and burn all result in facial tissue loss and deformity. The traditional reconstructive ladder-direct closure, skin grafts, local flaps, distant flaps, free flaps-still applies to reconstruction of the face as in any area of the human body [1]. In facial region, both aesthetic and functional reconstruction are needed to achieve the best result. This article will discuss the use of microsurgery in managing these problems. We review the replantation of facial organs, free flap reconstruction, especially anterolateral thigh flap, and concepts of perforator flaps. Finally, facial transplantation is reviewed.

\section{Amputation of Scalp and Small Facial Parts (Ear, Nose, Lip)}

\subsection{Introduction}

Amputation of scalp, ear, nose or lip is not common. The results of using the composite graft technique to replant these parts are not predictable and complete failure is

\footnotetext{
${ }^{*}$ Corresponding author.
}

very common [2,3]. Because there is nothing superior to the original tissue with satisfactory functional and aesthetic results, microsurgical replantation of the amputated scalp and small facial parts (ear, nose and lip) should always be attempted first [4,5]. When suitable donor and recipient vessels are available, replantation of any severed tissue may be successful. However, replantation of these body parts remains technically challenging because the arteries and veins encountered are extremely small and lack of suitable veins for drainage is common [6,7]. All efforts should be made to repair these injuries microsurgically, because it currently offers the best reconstructive solution and yields a more reliable outcome [4, 5,8-10].

\subsection{History of Replantation}

The first successful replantation started from an arm amputation four decades ago [11]. After that, revascularization of incompletely severed digits was proven feasible by Kleinert and Kasdan in 1965 [12]. The first successful digital replantation was performed by Komatsu and Tamai in 1968 [13]. The facial replantation started from 1974, when the first successful replantation of the 
scalp was done by Miller et al. [14]. Later, James was the first to microsurgically replant the upper lip and nose in a 3 -year-old girl bitten by a dog [8]. Finally, in 1980, Pennington et al. used vein grafts and the superficial temporal vessels to replant an ear [15].

\subsection{General Principles for Scalp and Small Facial Parts Replantation}

Decreasing warm ischemia time, aggressive debridement and good vascularization of the tissue by microvascular anastomosis are the fundamental principles to gain favorable results. Artery repair requires $10-\mathrm{O}$ to $11-\mathrm{O} \mathrm{Ny}-$ lon and delicate microsurgical technique. Vein grafts are usually needed to bridge artery or vein defects due to avulsion, vessel stump loss after debridement and for tensionless closure [16-18]. An absence of venous outflow in small part replantation often results in complete failure [7]. Various alternatives have been mentioned to relieve venous congestion, such as milking, pin pricking, using medicinal leeches [19-21], an artery-to-vein shunting/fistula [22-24]. Chemical leeches [4,25] were proposed due to unavailability of medicinal leeches, risk of systemic infection, and difficulties with patients' acceptance. This allows venous blood to escape into the dressing while an adequate venous microcirculation is being reestablished [26]. Blood loss could be great and blood transfusion might be needed to maintain adequate hemoglobin level. Post-operative care is very important. Venous congestion usually mandates early intervention including drainage, reopening of the drainage channels with a needle, flushing soaking with heparin sodium solution until the collateral circulation establishes. Others include controlling infection, increasing blood volume, dilating vessels and special nursing [27]. The benefit of drugs such as prostaglandin E1 or hyperbaric oxygen therapy is not clear [28].

\subsection{Scalp Replantation}

Scalping injuries are rare. One-stage successful replantation of a partial or total avulsed scalp by microvascular anastomosis offers a superior result to any other types of reconstruction and provides substantial economic, social, and psychological benefits [29,30]. Every effort should be made to save the avulsed scalp, even in severely damaged and juvenile cases [31,32]. The success rate was 90 percent $[33,34]$ and skillful and experienced surgeon had more favorable outcome [7].

The commonly used arteries are temporal artery and occipital artery. The temporal artery has reasonable size and thus is used primarily [34,35]. Occipital artery is an option [36,37] but the anatomic position is not as convenient as superficial temporal artery due to possible coexisting cervical spine injury [38]. The entire scalp can survive based on a single artery and a single vein if there is adequate flow [39-42], but two sets of arteries seems to be safer than single set $[17,43]$. Vein grafts are usually needed. If arterioarterial repair is not possible, arteriovenous anastomosis can be done [44]. Anastomosing a few veins before arterial anastomosis helps to reduce the blood loss from the edges of the avulsed segment [45].

A good venous return would be more important for a successful replantation than the number of vessels anastomosed [37]. To improve venous return, surgeons may use many veins [46,47], leeches [48], or incise the skin to allow venous bleeding [5]. Using a second artery in the scalp for anastomosis to a recipient vein to allow egress of blood was also reported [49]. Hematoma formation under the replanted scalp is one of the commonly reported complications which lead to compromise of the tissue $[17,50]$.

Despite the 90 - 95 percent success rate, partial loss of the tissue is fairly common about 30 percent of the replanted tissue $[17,18,37,49]$. Additional revision of replanted tissue is frequently needed [29]. Secondary revision by tissue expansion of the surviving portion of the scalp replant may be the best method of correcting any residual alopecia [30,37,51,52]. All reports showed good return of hair growth in the surviving segments of scalp. Even though the scalp was turned 180 degree for any reasons, the hair growth is also good $[53,54]$.

Nerve repair is not easy in scalp replantation due to avulsion [55]. Only 35\% can be repaired in a 20-cases study [16]. The sensory return ranges from protective sensation without nerve repair [34] to $15 \mathrm{~mm}$ at two-year follow-up with nerve anastomosis [49]. However, Ueda reported sensory recovery with no nerve anastomosis eight months after surgery mainly from the area along the supraorbital nerve. Temporary sensory disorientation also presented. The cutaneous threshold in the SemmesWeinstein test finally recovered to almost the normal range, possibly due to spontaneous nerve anastomosis by chemotaxis [55].

\subsection{Ear, Nose, Lip, and Eyebrow (Small Parts) Replantation}

\subsubsection{Introduction}

The ear, nose, and lip protrude outward from the face, thus making them readily injured by trauma. These injuries occur due to animal bites (dogs [8], horse [56]), industrial accident $[57,58]$, and a lesser number from human bites [4,59]. Traumatic amputation of the ear, nose, lip [60] and eyebrow [5] remains unusual and present a significant reconstructive challenge. Successful microsurgical replantation of all these tissues is still the most effective option and obviates the problems associated with their loss [5,21,23,61-63]. 


\subsubsection{Artery and Associated Problems}

The primary arterial supply to the ear is from branches of superficial temporal artery at about the level of the tragus. Superficial temporal artery and posterior auricular artery can be used for ear replantation [64]. The small branches form an arterial arcade to supply both the anterior and posterior surface of the ear then communicates inferiorly with the branches of the posterior auricular artery [65]. Therefore, usually only one artery anastomosis is enough for ear replantation. The artery size is usually $0.5-0.7$ $\mathrm{mm}$ but primary anastomosis is possible by skilled microsurgeons [5]. If the ear is avulsed with vessel loss, primary anastomosis is not possible and vein grafts should be used or the temporal artery can be freed up and brought posteriorly as a vascular leash for anastomosis [64].

Arterial anastomosis in the amputated lip is by the labial artery [56,60,66]. In nasal replantation, labial artery, the left nasal branch of the facial artery and the right nasal branch of the left supratrochlear artery [62], a branch of the angular or lateral nasal artery [67], the dorsal nasal artery $[10,68]$, and a branch of the anterior ethmoidal artery, an internal artery of the nose, running perpendicularly in the intercartilaginous region have been used as recipient arteries. If there is no definite artery in the amputated part, arterial-venous fistula can be performed [5]. Low oxygen requirement of the cartilages can be an advantage in nose replantation [67] and ear replantation for better tolerance of long ischemia time.

\subsubsection{Venous Drainage Problems}

Like scalp replantation, the real problem with small part replantation is the venous drainage. The veins on the posterior ear surface are extremely small and are few in number. Transillumination to the amputated ear might show veins in young children ear replantation [69]. Venovenous and arteriovenous anastomosis should be attempted first [70]. If no veins are available, replantation can be successful by using leeches for venous drainage [71-76], open venous drainage [61] or chemical leech with intrareplant subcutaneous heparin injections for lip [5,59], making stab wounds in the posterior ear [77-79]. Almost all successful small part replantation have used heparin and bleeding should be monitored. Most patients will require transfusion with this approach, which averages approximately 6 units [60]. Most reported cases were successful and failure was usually due to inadequate venous drainage.

\subsubsection{Adjunct Procedures}

It is important to know adjunctive reconstructive techniques in order to salvage amputated cartilage when vascular repair is impossible or fail or partial necrosis occurs. The ear cartilage can be salvaged by wrapping it in the temporoparietal fascia [5,80]. The nasolabial flap was used to provide coverage of nasal alae when partial loss of the replant occurred after microvascular replantation [5].

\subsubsection{Success Rate and Functional Outcome}

The success rate is difficult to estimate due to relatively few reports. The largest reported series from 12 institutions contains only 13 patients who required lip replantation [60]. Nasal amputation amenable to replantation also has been reported only a few times (one patient had both the lip and nose amputated) [5,21,23,61,62]. Successful eyebrow revascularization using a branch of temporal artery $(0.6 \mathrm{~mm})$ had been reported only one time [5]. However, with a successful arterial anastomosis and the use of heparin and leeches, success should be expected. Even with partial survival of the replanted ear, the cosmetic results are usually superior to other reconstruction methods.

A 30-year follow-up of the first ear replantation by Pennington et al. showed long-term superior aesthetic quality and durability result. The degree of minor aesthetic change in shape depends on the extent of original injury, and proportion of the amount of tissue loss. Generally, cartilage atrophy didn't occur and the stability was not affected if there is little cartilage loss but the size and shape might be changed due to conchal distortion and scar contracture. Sensory recovery is complete within 3 years and canal stenosis is preventable with a silicone stent for 3 months [81].

The patient after lip replantation regained sensation and motor function even though no motor nerve and sensory nerve were repaired. Electromyography showed almost normal vermilion muscle motility and static twopoint discrimination was $6 \mathrm{~mm}$ in two cases of lower lip replantation with 7 to 8 months of follow-up [4,59]. Another case could even purse his lips and regained sensation and the use of orbicularis oris and mentalis muscle [56]. Because of the potential superior cosmetic and functional results following replantation, we recommend aggressive microsurgical attempts at arterial and venous anastomosis following traumatic amputation.

\section{Using the Microsurgical Free Flaps for Facial Trauma/Defect Reconstruction}

\subsection{Traditional Methods of Reconstruction}

Trauma and cancer ablation result in huge facial defects and microsurgical free flaps are the current trend of reconstruction. Since the first description of free groin flap transfer in 1973 [82] and free gracilis flap transfer in 1976 [83], microsurgical free flaps have been in clinical use for more than three decades and is a routine practice in many hospitals nowadays. The other well-known flap 
is free latissimus dorsi muscle flap, which can provide large mass of well vascularized tissue [84] to tamponade dead space. Rectus abdominis muscle flap is also popular for defect coverage (Figures 1 and 2). Because the muscle flaps are bulky and donor-site morbidity is common, development of muscle-sparing flaps like the fasciocutaneous flaps solved the problem. Here we emphasize the anterolateral thigh flap.

\subsection{Anterolateral Thigh (ALT) Flap}

Since its first description by Song et al. in 1984 [85], the anterolateral thigh flap has been gaining popularity among microsurgeons. It is versatile and reliable in head and neck surgery because reconstruction of some of the soft tissue defects requires thin, pliable tissue and may encounter different defects at the same time [86-90] (Figure 3). The anterolateral thigh flap can be thinned using simple and effective procedures [89,91,92]. The distal stump of the pedicle can be used to anastomose vascularized bone or another soft tissue flap, thus creating "mosaic" flaps [93]. Mostly used in facial reconstruction is combining the vascularized fibula bone flap for mandibular reconstruction [94]. When more complex reconstruction is needed, the "chimeric" flaps in a freestyle fashion based on the lateral femoral circumflex axis to include skin flaps, vastus lateralis muscle flap and tensor fasciae latae flap in combination can reconstruct different defects in the same region at the same time [92, 95-99]. Finally, if more than one perforator is available, the skin flap can be separated into smaller skin flaps, each one of them based on one perforator.

The maximum dimensions of the flap that can be harvested are still debated. According to Koshima et al., the skin paddle could be up to $35 \mathrm{~cm}$ in length and $25 \mathrm{~cm}$ in width based on a single dominant perforator [100]. The axial vessel supplying the anterolateral thigh (ALT) flap is the lateral circumflex femoral artery (LCFA). Its de-

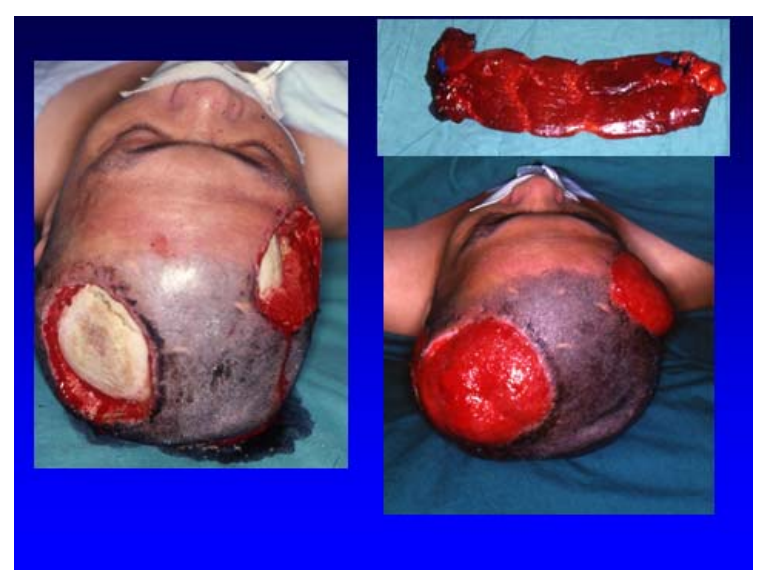

Figure 1. Electric burn resulted skull bone exposure (left). A rectus abdominis muscle flap was harvested for reconstruction (right upper). The flap survived (right lower).

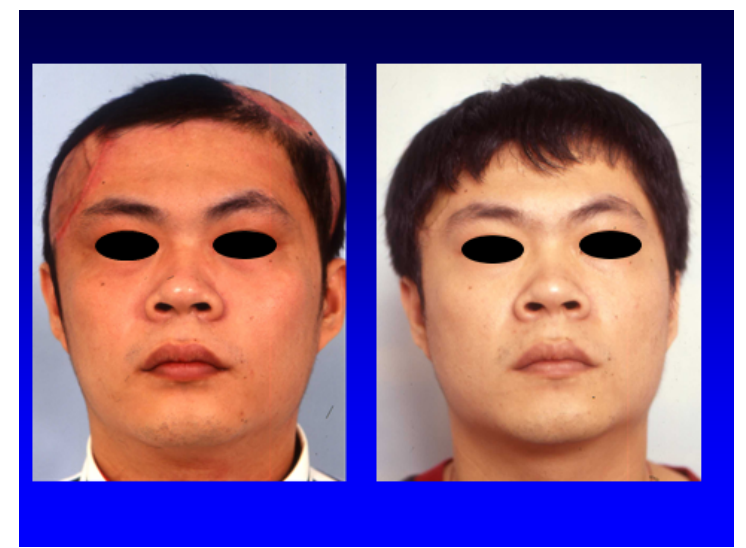

Figure 2. The alopecia was reconstructed with tissue expander technique and advancement flap.

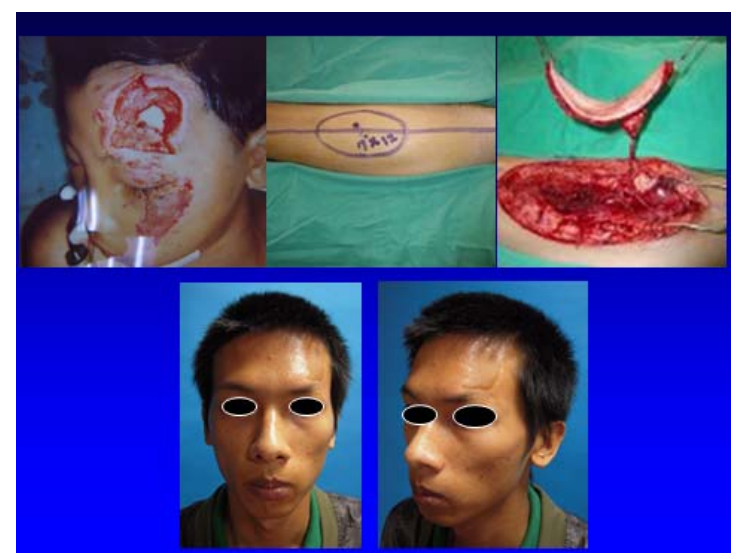

Figure 3. A 15 y/o male suffered from left frontal skin defect after avulsion injury (upper left). An ALT perforator flap was harvested for reconstruction (upper middle and right). Results of 10 years after reconstruction (lower left and right).

scending branch sends perforators through the septum (septocutaneous) between vastus lateralis and rectus femoris or through the vastus lateralis muscle (musculocutaneous) to supply the flap. The musculocutaneous perforators are the most common type and are responsible for blood supply in more than $86 \%$ of the cases and the septocutaneous perforators are responsible in about $12 \%$ of cases $[88,101,102]$.

\subsection{Operative Technique Review of ALT Flap}

\subsubsection{Marking [103]}

The line between the anterior superior iliac spine and the lateral border of the patella represents the axis of the flap and corresponds roughly with the intermuscular septum between the rectus femoris and vastus lateralis muscles. The main perforators for the anterolateral thigh flap are identified with the Doppler. They are usually located within an area of $5 \mathrm{~cm}$ around the midpoint of the axis of the flap [88]. The dissection is from either medial or la- 
teral approach.

\subsubsection{Medial Approach [104]}

The medial approach makes incision medial to the axis line, usually at the line between the inguinal femoral pulse to the uppermost point of patella. The dissection is done from medial to lateral and perforators are identified and looped. The shape hand size of the flap doesn't need to be determined at this time. When all dissections are finished, the flap can then be designed according to the size, shape and three dimensional relationship of defect, especially when chimeric flaps are needed.

\subsubsection{Lateral Approach}

The lateral approach mandates the lateral margin of the flap to be determined first after Doppler study [103]. The lateral margin of the flap is cut then perforators are searched. The dissection changes to the medial side and completes from medial to lateral. It is thought to be safer as the perforators have already been identified from the lateral side and their damage is almost always avoided. However, if the perforator is not sizable or damaged, intra-operative change of the surgical plan to more proximal or distal perforators might be struggling due to already incised lateral margin.

\subsubsection{Dissection}

Dissection under loupe magnification $(2.5 \times$ to $4.5 \times)$ is mandatory. Including more than one perforator initially provides a backup if one perforator is damaged during dissection. Dissection of the perforator(s) to the main pedicle is performed using the "deroofing" technique by cutting the muscles along the length of their fibers to liberate the perforators under stretching of the muscle fibers with instruments [104-106]. The numerous tiny branches that the perforators give to the muscle have to be ligated as far from the perforator as possible by using clips. If an unusually large branch were met while dissecting a perforator, it should not be ligated immediately because it may come from the next nearest perforator with a long intramuscular route. Patience is needed in perforator dissection [107].

\subsubsection{Avoiding Damage and Twisting of Perforators during Dissection}

Irrigating the perforator with $2 \%$ Xylocaine helps to prevent vasospasm and dryness. The perforator should not be stretched and pulsation transmitted throughout the length of the perforator should be observed to ensure that the perforator is perfusing the flap. Including more than one perforators and include a small muscle cuff or fascia at the point of entrance of the perforator to the flap help to define the original orientation of vessels and avoid twisting of the pedicle. Also, a fine suture that connects a branch stump of the main pedicle and the flap may prevent torsion and twisting of the pedicle. This suture should be removed after inset of the flap [101] to prevent pedicle kinking around the suture point. Some surgeon also include about $5 \mathrm{~mm}$ muscle cuff around the pedicle to prevent vasospasm and keep orientation of the vessel.

\subsubsection{Donor Site Closure}

The concept that donor site can be closed directly when the width of the flap is less than $8 \mathrm{~cm}$ had been applied for a long time. If the flap width is more than $8 \mathrm{~cm}$, the donor site should be closed with a skin graft to avoid compartment syndrome or skin necrosis [101]. In clinical practice, this is not always true. Boca et al. proposed a more precise evaluation that primary closure can be achieved if the flap width-to-thigh circumference ration is less than 16 percent [108]. We proposed no hesitation for skin grafting if the donor site can't be closed to prevent necrosis of thigh muscles.

\subsubsection{Advantages and Disadvantages of the Anterolateral Thigh Flap}

The anterolateral thigh flap has many advantages over other free flaps including 1) long vascular pedicle; 2) large and pliable skin paddle with good color and texture matching [109]; 3) potential sensory flap by inclusion of the lateral femoral cutaneous nerve [82,88]; (minimal donor-site morbidity even when harvested as a myocutaneous flap [110,111]; 4) bridging vascular gap by flowthrough flap [112]; 5) including of the vastus lateralis muscle to fill dead spaces and help avoid infection after surgery [110]; 6) shortening of operation time by twoteam approach.

The disadvantages of the anterolateral thigh flap include 1) anatomic variations; 2) hair growth in some male patient and influence on appearance and in intraoral reconstruction; 3) variable thickness of the flap. The Asian population has most reported series with average thickness $7 \mathrm{~mm}$ thick [100,113], which is about half of those in the Western population [114]; 4) inconsistent result of thinning. About $3-4 \mathrm{~mm}$ or $4-5 \mathrm{~mm}$ can be achieved in one stage [91], but one stage thinning of the flap in the Western population has resulted in high rates of partial or complete flap necrosis especially in flaps more than $150 \mathrm{~cm}^{2}$ [115,116]. Therefore, thinning should be more conservative in these population or placed in secondary stage with suction lipectomy [117,118]; 5) no sizeable perforator in $1 \%$ - $2 \%$ of ALT flap [119]. When this happens we surgeons can do as follows:

1) Explore the transverse branch of LCFA in the proximal lateral thigh to harvest a tensor fascia lata perforator flap.

2) Proceed dissection medial to the incision to elevate 
an anteromedial thigh (AMT) flap as a free-style free flap.

3) Elevate a free muscle flap based on the LCFA system with the coverage of skin graft.

4) Abandon the dissection and seek for another donor site. By following the proposed alternative choices, the reconstruction could be completed with a higher success rate.

\section{Perforator Flaps}

Due to refinements in surgical technique and instrumenttation, the free flap survival rate at present is more than $95 \%$ in most centers. The microsurgeons are nowadays more interested in improving the aesthetic and functional results and reducing donor-site morbidity.

\subsection{Introduction and History of Perforator Flaps}

The concept of perforator flaps originated from the anatomic study of Taylor and Palmer [120]. The study described mean of 276 cutaneous perforators of $0.5 \mathrm{~mm}$ diameter or greater in the whole body. They connect to each other by a system of "choke vessels" to form a continuous network in supra-fascia tissue level to the skin [120]. Later on, Taylor et al. demonstrated using a Doppler device to plan a skin flap around any of these perforators [121]. Wei et al. clarified the definition of perforators as those cutaneous vessels that penetrate the muscle and then pierce the fascia to reach the skin [122]. Since then, flap surgery has entered a new era, and numerous perforator flaps have been described [123, 124].

\subsection{Free Style Perforator Flaps}

Free-style perforator flaps harvested in a free-style manner, based only on the preoperative survey of Doppler signals, can be raised from any anatomic region [125] and transposed locally to cover defects in adjacent anatomic regions with single-Free-Style Local Perforator Flap (FSLPF), multi-FSLPF and peninsular-FSLPF [126], or free-style free perforator flaps [127]. Free-style local perforator flaps may provide better aesthetic results than non-perforator based flaps for the coverage of a defect because the skin around the flaps has similar texture, thickness, color and least donor-site morbidity [125], especially in facial reconstruction. The length of the pedicle and the size of the vessel diameter could be large enough to obviate the supramicrosurgery techniques [125, 128]. Backup vessels and backup flaps are prepared if possible when there is no suitable vessel or damage of the pedicle [128].

\subsection{Limitations}

The microsurgeons need to have superior microsurgical skills and be familiar with perforator flaps and intramuscular perforator dissection before attempting a free-style perforator flap; therefore, it is not an operation for the beginner. Moreover, surgeons need to be experienced in using the Doppler device. For example, in areas where large underlying vessels are present, the signal of the main vessel will obscure the signal of the smaller perforators [129]. Other limitations of the technique are 1) possible unpredictable course of perforators [128]; 2) possible small and short perforators that are difficult to harvest or inset; and 3) more conservative intraoperative flap thinning compared with that of conventional flaps; 4) not appropriate for complex defects which require chimeric flaps [128]; 5) inaccurate and insufficient Doppler investigation in lower back-gluteal region and immature infant vascular system [126].

\section{Facial Allotransplantation}

\subsection{Introduction}

Despite the advanced development of free ALT flaps and perforator flaps, there are still situations that can't be solved by flaps alone. Rifle suicide gun-shot wounds [130], neurofibromotosis [131], animal bites, cancer ablation and burn injury may result in extensive facial deformity (loss of at least $25 \%$ of facial surface or important facial units such as nose and lips) [132] and complex naso-orbital-maxillary defect. Free tissue transfer and numerous autologous flaps can obliterate dead space but cannot match the delicate details of a completely amputated nose and a functional upper lip. Ultimately, the outcome of simulating mimetic musculature influencing “one’s unique appearance” is disappointing [130,133].

Face transplantation has been shown thus far to be a viable option in some patients suffering severe facial deficits which are not amenable to current reconstructive techniques [134]. In order to achieve the "replacing like with like" principle, many centers in France, China, United States, and Spain had performed facial transplanttation to solve the problem [130,135-140]. From November 2005 to April 2010, 11 facial transplants had been performed worldwide [141]. In the first three cases, only soft tissue was transferred. The fourth case (also the first case in United States) included maxilla and palate for near-total facial transplantation [142]. The promising subspecialty of composite tissue allotransplantation, particularly maxillofacial allotransplantation, may soon become a clinical standard [133,143].

\subsection{Selection of Patients, Operation and Post-Operative Care}

Before operation, patient selection is important. The Cleveland clinic used the parameters of Functional status, Aesthetic deficit, Comorbidities, Exposed tissue, Surgi- 
cal history to develop a FACES score to objectively stratify face transplant candidates for their facial deficit during multiple steps throughout the screening process [134]. The surgical aspect of facial transplantation involves complex vascular anatomic study, mock surgery and surgical techniques [140,142]. The post-operative immunosuppression with antithymocyte globulin, tacrolimus, and mycophenolate mofetil [130], methylprednisolone [139] parallels the kidney transplantation [144]. Cytomegalovirus and pneumocystis prophylaxis [139] are necessary when indicated. Acute rejection is common and oral mucosa has earlier predictor of acute rejection episodes than the skin because of being more antigenic [144]. Biopsy of mucosa is easy and scarless. The risks of mandatory lifelong immunosuppression should be deliberated by each institution's multidisciplinary face transplant team [134].

\subsection{Outcome}

Gordon et al. reviewed all seven cases of facial transplant from 2005 to 2009 [134]. Overall long-term function of facial alloflaps has been reported to be satisfactory. Sensory recovery ranges between 3 and 6 months, and acceptable motor recovery ranges between 9 and 12 months. A cost analysis done by the Cleveland clinic for the first Unites States face transplant showed similar considerable cost to multiple conventional reconstructions. However, it is priceless to alleviate psychological and physiological suffering, better functional recovery and fulfill the long-lasting hope for social reintegration [145].

Ethic issues of facial transplantation are still being debated [146] but recent reports showed good psycho-societal outcome, quality of life and subject benefits against subject risks [147]. The benefits had been maximized and harms minimized through subject selection, team expertise, and preparation [134,148].

Facial transplantation reconstruct the function and the aesthetics at the same time, thus changed the traditional reconstruction ladder. However, to popularize facial transplantation still needs much more effort to organize institutions, a lot of medical and paramedical team works, organ procurement, surgical simulation and mock surgery techniques, which have been described above.

\section{Conclusion}

Application of microsurgery in facial trauma reconstruction started from replantation of amputated parts, progressed to free flaps, perforator flaps then finally facial allotransplantation in recent three decades. Surgeons in managing facial trauma should keep all these methods in mind to achieve better cosmetic and functional results. Replantation first, free flaps depending on the defect, and facial transplantation when extensive defect make the reconstruction ladder of managing complicated facial trauma using the microsurgery. Knowing the limits of these methods might stimulate more innovation and refinement. More and more facial transplantation are being performed worldwide. We expect to see it becoming as popular as free flap surgery.

\section{REFERENCES}

[1] S. J. Mathes and F. Nahai, "The Reconstructive Triangle, a Paradigm for Surgical Decision Making," In: S. J. Mathes and F. Nahai, Eds., Reconstructive Surgery: Principles, Anatomy and Technique, Churchill Livingstone and Quality Medical Publishing Inc., New York, 1982, pp. 9-36.

[2] D. F. Cort, “Nasal Tip Replantation,” Plastic \& Reconstructive Surgery, Vol. 52, No. 2, 1973, pp. 194-196. doi:10.1097/00006534-197308000-00024

[3] W. C. Grabb and R. O. Dingman, "The Fate of Amputated Tissues of the Head and Neck Following Replacement," Plastic \& Reconstructive Surgery, Vol. 49, No.1, 1972, pp. 28-32. doi:10.1097/00006534-197201000-00005

[4] S. F. Jeng, F. C. Wei and M. S. Noordhoff, "Successful Replantation of a Bitten-Off Vermilion of the Lower Lip by Microvascular Anastomosis: Case Report,” Journal of Trauma-Injury Infection \& Critical Care, Vol. 33, No. 6, 1992, pp. 914-916. doi:10.1097/00005373-199212000-00023

[5] S. F. Jeng, F. C. Wei and M. S. Noordhoff, "Replantation of Amputated Facial Tissues with Microvascular Anastomosis," Microsurgery, Vol. 15, No. 5, 1994, pp. 327333. doi:10.1002/micr.1920150508

[6] S. Kim, H. Jeong, T. H. Choi and J. S. Kim, "Successful Re-Plantation of an Amputated Nasal Segment by Supermicrosurgery: A Case Report and Review of the Literature," Journal of Plastic, Reconstructive \& Aesthetic Surgery, Vol. 63, No. 4, 2010, pp. e380-e383. doi:10.1016/j.bjps.2009.10.012

[7] B. Strauch, L. A. Sharzer, J. Petro and B. Greenstein, "Replantation of Amputated Parts of the Penis, Nose, Ear, and Scalp," Clinics in Plastic Surgery, Vol. 10, No. 1, 1983, pp. 115-124.

[8] N. J. James, "Survival of Large Replanted Segment of Upper Lip and Nose. Case Report,” Plastic \& Reconstructive Surgery, Vol. 58, No. 5, 1976, pp. 623-625. doi:10.1097/00006534-197611000-00022

[9] W. C. Pederson, "Replantation,” Plastic \& Reconstructive Surgery, Vol. 107, No. 3, 2001, pp. 823-841. doi:10.1097/00006534-200103000-00027

[10] R. L. Flores, A. Hazen, R. D. Galiano, A. M. Klapper and J. P. Levine, "Nonextremity Replantation: The Management of Amputations of the Facial Parts and Testicle," Clinics in Plastic Surgery, Vol. 34, No. 2, 2007, pp. 197210. doi:10.1016/j.cps.2006.10.002

[11] R. A. Malt, “Clinical Aspects of Restoring Limbs,” Ad- 
vances in Surgery, Vol. 2, 1966, pp. 19-33.

[12] H. E. Kleinert and M. L. Kasdan, “Anastomosis of Digital Vessels,” Journal of the Kentucky Medical Association, Vol. 63, 1965, pp. 106-108.

[13] S. Komatsu and S. Tamai, "Successful Replantation of a Completely Cut-Off Thumb,” Plastic \& Reconstructive Surgery, Vol. 42, 1968, pp. 374-377. doi:10.1097/00006534-196810000-00021

[14] G. D. Miller, E. J. Austee and J. A. Snell, "Successful Replantation of an Avulsed Scalp by Microvascular Anastomoses," Plastic \& Reconstructive Surgery, Vol. 58, No. 2, 1976, pp. 133-136. doi:10.1097/00006534-197608000-00001

[15] D. G. Pennington, M. F. Lai and A. D. Pelly, "Successful Replantation of a Completely Avulsed Ear by Microvascular Anastomosis," Plastic \& Reconstructive Surgery, Vol. 65, No. 6, 1980, pp. 820-823. doi:10.1097/00006534-198006000-00017

[16] K. Cheng, S. Zhou, K. Jiang, S. Wang, J. Dong, W. Huang and T. Chang, "Microsurgical Replantation of the Avulsed Scalp: Report of 20 Cases," Plastic \& Reconstructive Surgery, Vol. 97, No. 6, 1996, pp. 1099-1106. doi:10.1097/00006534-199605000-00001

[17] J. McCann, et al., "Microvascular Replantation of a Completely Avulsed Scalp,” Microsurgery, Vol. 15, No. 9, 1994, pp. 639-642. doi:10.1002/micr.1920150907

[18] K. Arashiro, H. Ohtsuka, K. Ohtani, et al., "Entire Scalp Replantation: Case report and Review of the Literature," Journal of Reconstructive Microsurgery, Vol. 11, No. 4, 1995, pp. 245-250. doi:10.1055/s-2007-1006539

[19] K. L. Mutimer, J. C. Banis and J. Upton, "Microsurgical Reattachment of Totally Amputated Ears,” Plastic \& Reconstructive Surgery, Vol. 79, No. 4, 1987, pp. 535-541. doi:10.1097/00006534-198704000-00003

[20] J. P. Anthony, W. C. Lineaweaver, J. W. Davis, et al., "Quantitative Fluorimetric Effects of Leeching on a Replanted Ear,” Microsurgery, Vol. 10, No. 3, 1989, pp. 167-169. doi:10.1002/micr.1920100304

[21] Z. Niazi, T. C. Lee, P. Eadie and D. Lawlor, "Successful Replantation of Nose by Microsurgical Technique, and Review of Literature,” British Journal of Plastic Surgery, Vol. 43, No. 5, 1990, pp. 617-620.

[22] A. R. Smith, G. J. Sonneveld and J. C. van der Meulen, "AV Anastomosis as a Solution for Absent Venous Drainage in Replantation Surgery," Plastic \& Reconstructive Surgery, Vol. 71, No. 4, 1983, pp. 525-532. doi:10.1097/00006534-198304000-00013

[23] S. Tajima, K. Ueda and Y. Tanaka, "Successful Replantation of a Bitten-Off Nose by Microvascular Anastomosis,” Microsurgery, Vol. 10, No. 5, 1989, pp. 5-7. doi:10.1002/micr.1920100103

[24] S. F. Jeng, F. C. Wei and K. T. Chen, "Successful Replantation of an Amputated Nasal Tip by Microvascular Anastomosis," Plastic \& Reconstructive Surgery, Vol. 87, No. 6, 1991, pp. 118-120. doi:10.1097/00006534-199106000-00017

[25] G. R. Barnett, G. I. Taylor and K. L. Mutimer, "The 'Chemical Leech’: Intra-Replant Subcutaneous Heparin as an Alternative to Venous Anastomosis. Report of Three Cases,” British Journal of Plastic Surgery, Vol. 42, No. 5, 1989, pp. 556-558. doi:10.1016/0007-1226(89)90044-1

[26] T. Nakajima, "How Soon Do Venous Drainage Channels Develop at the Periphery of a Free Flap? A Study in Rats,” British Journal of Plastic Surgery, Vol. 31, No. 4, 1978, pp. 300-308. doi:10.1016/S0007-1226(78)90115-7

[27] Y. Liang, X. Li, L. Gu, Y. Xiao, et al., "Successful Auricle Replantation via Microvascular Anastomosis 10h after Complete Avulsion,” Acta Oto-Laryngologica, Vol. 124, No. 5, 2004, pp. 645-648. doi:10.1080/00016480410016603

[28] A. Steffen, R. Katzbach and S. Klaiber, “A Comparison of Ear Reattachment Methods: A Review of 25 Years since Pennington,” Plastic and Reconstructive Surgery, Vol. 118, No. 6, 2006, pp. 1358-1364. doi:10.1097/01.prs.0000239539.98956.b0

[29] M. Topalan and I. Ermis, "Replantation and Triple Expansion of a Three-Piece Total Scalp Avulsion: Six-Year Follow-up," Annals of Plastic Surgery, Vol. 46, No. 2, 2001, pp. 167-169. doi:10.1097/00000637-200102000-00015

[30] G. G. Hallock, "Secondary Expansion of a Replanted Scalp Salvaged by an Intrinsic Arteriovenous Shunt," Plastic \& Reconstructive Surgery, Vol. 103, No. 7, 1999, pp. 1957-1960. doi:10.1097/00006534-199906000-00021

[31] I. Fogdestam and J. Lilja, "Microsurgical Replantation of a Total Scalp Avulsion. Case Report,” Scandinavian Journal of Plastic \& Reconstructive Surgery, Vol. 20, No. 3, 1986, pp. 319-322. doi:10.3109/02844318609004494

[32] T. Liu, J. Dong, J. Wang and J. Yang, "Microsurgical Replantation for Child Total Scalp Avulsion,” Journal of Craniofacial Surgery, Vol. 20, No.1, 2009, pp. 81-84. doi:10.1097/SCS.0b013e3181843326

[33] B. S. Alpert, H. J. Buncke Jr. and S. J. Mathes, "Surgical Treatment of the Totally Avulsed Scalp,” Clinics in Plastic Surgery, Vol. 9, No. 2, 1982, pp. 145-159.

[34] F. Nahai, T. R. Hester and M. J. Jurkiewicz, "Microsurgical Replantation of the Scalp," Journal of Trauma-Injury Infection \& Critical Care, Vol. 25, No. 9, 1985, pp. 897-902. doi:10.1097/00005373-198509000-00014

[35] J. E. Gatti and D. LaRossa, "Scalp Avulsions and Review of Successful Replantation,” Annals of Plastic Surgery, Vol. 6, No. 2, 1981, pp. 127-131. doi:10.1097/00000637-198102000-00007

[36] S. Sakai, S. Soeda and Y. Ishii, "Avulsion of the Scalp: Which One Is the Best Artery for Anastomosis?” Annals of Plastic Surgery, Vol. 24, No. 4, 1990, pp. 350-353. doi:10.1097/00000637-199004000-00009

[37] J. W. Yin, J. M. Matsuo, C. H. Hsieh, M. C. Yeh, W. C. Liao and S. F. Jeng, "Replantation of Total Avulsed Scalp with Microsurgery: Experience of Eight Cases and Literature Review," Journal of Trauma-Injury, Infection, and Critical Care, Vol. 64, No. 3, 2008, pp. 796-802. doi:10.1097/TA.0b013e3180341fdb

[38] B. J. Wilhelmi, R. H. Kang, K. Movassaghi, P. A. Ganchi and W. P. Lee, "First Successful Replantation of Face and 
Scalp with Single-Artery Repair: Model for Face and Scalp Transplantation," Annals of Plastic Surgery, Vol. 50, No. 5, 2003, pp. 535-540. doi:10.1097/01.SAP.0000037875.69379.56

[39] F. Nahai, J. Hurteau and L. O. Vasconez, "Replantation of an Entire Scalp and Ear by Microvascular Anastomoses of Only 1 Artery and 1 Vein," British Journal of Plastic Surgery, Vol. 31, No. 4, 1978, p. 339. doi:10.1016/0007-1226(78)90122-4

[40] D. P. Tantri, A. L. Cervino and N. Tabbal, "Replantation of the Totally Avulsed Scalp," Journal of Trauma-Injury Infection \& Critical Care, Vol. 20, No. 4, 1980, pp. 350-352.

[41] C. K. Chou, S. D. Lin, C. C. Yang, C. S. Lai and G. T. Lin, "Microsurgical Replantation of Avulsed Scalp-Two Cases Report,” Kaohsiung Journal of Medical Sciences, Vol. 8, No. 5, 1992, pp. 285-289.

[42] S. Eren, J. Hess and G. C. Larkin, “Total Scalp Replantation Based on One Artery and One Vein,” Microsurgery, Vol. 14, No. 4, 1993, pp. 266-271. doi:10.1002/micr.1920140410

[43] S, Zhou, T. S. Chang, W. X. Guan, et al, "Microsurgical Replantation of the Avulsed Scalp: Report of Six Cases," Journal of Reconstructive Microsurgery, Vol. 9, No. 2, 1993, pp. 121-125.

[44] S. F. Morris, K. A. MacGill and G. I. Taylor, "Scalp Replantation by Arterialised Venous Network Fow-through," British Journal of Plastic Surgery, Vol. 45, No. 3, 1992, pp. 187-192. doi:10.1016/0007-1226(92)90074-8

[45] A. Thomas, V. Obed, A. Murarka and G. Malhotra, "Total Face and Scalp Replantation,” Plastic \& Reconstructive Surgery, Vol. 102, No. 6, 1998, pp. 2085-2087. doi:10.1097/00006534-199811000-00041

[46] A. Yaffe and A. Shvoron, "Successful Replantation of a Totally Avulsed Scalp," Journal of Reconstructive Microsurgery, Vol. 2, No. 3, 1986, pp. 171-173. doi:10.1055/s-2007-1007019

[47] H. Y. Kaplan, B. Yaffe and A. Borenstein, "Single Artery Replantation of Totally Avulsed Scalp,” Injury, Vol. 24, No. 7, 1993, pp. 488-490. doi:10.1016/0020-1383(93)90157-2

[48] H. P. Henderson, B. Matti, A. G. Laing, S. Morelli and L. Sully, "Avulsion of the Scalp Treated by Microvascular Repair: The Use of Leeches for Post-Operative Decongestion,” British Journal of Plastic Surgery, Vol. 36, No. 2, 1983, pp. 235-239. doi:10.1016/0007-1226(83)90099-1

[49] I. C. Chen and H. L. Wan, "Microsurgical Replantation of Avulsed Scalps,” Journal of Reconstructive Microsurgery, Vol. 12, No. 2, 1996, pp. 105-112. doi:10.1055/s-2007-1006462

[50] E. Biemer, W. Stock, C. Wolfensberger, G. Ingianni and W. D. Götz, "Successful Replantation of a Totally Avulsed Scalp,” British Journal of Plastic Surgery, Vol. 32, No. 1, 1979, pp. 19-21. doi:10.1016/0007-1226(79)90054-7

[51] D. Maladry, B. Brabant, V. Berard, P. Dupuis and V. Mitz, "Secondary Expansion of a Totally Replanted Scalp for Aesthetic Adjustment," Plastic \& Reconstructive Surgery, Vol. 94, No. 7, 1994, pp. 1052-1054. doi:10.1097/00006534-199412000-00021

[52] B. C. Cho, D. H. Lee, J. W. Park, J. S. Byun and B. S. Baik, "Replantation of Avulsed Scalps and Secondary Aesthetic Correction,” Annals of Plastic Surgery, Vol. 44, No. 4, 2000, pp. 361-366. doi:10.1097/00000637-200044040-00002

[53] O. Libermanis, M. Kapickis and J. Krustins, “An Unusual Case of Microvascular Replantation of the Scalp," Plastic \& Reconstructive Surgery, Vol. 102, No. 6, 1998, pp. 2273-2274. doi:10.1097/00006534-199811000-00074

[54] H. Svensson and T. Njalsson, "Microsurgical Replantation of Partial Avulsion of the Scalp Scandinavian,” Journal of Plastic \& Reconstructive Surgery \& Hand Surgery, Vol. 29, No. 2, 1995, pp. 177-180. doi:10.3109/02844319509034335

[55] K. Ueda, T. Nomatsi, Y. Omiya and S. Tajima, "Replanted Scalp Recovers Normal Sensation without Nerve Anastomosis," Plastic \& Reconstructive Surgery, Vol. 106, No. 7, 2000, pp. 1651-1652. doi:10.1097/00006534-200012000-00041

[56] W. Schubert, B. Kimberley, G. Guzman-Stein and B. L. Cunningham, "Use of the Labial Artery for Replantation of the Lip and Chin,” Annals of Plastic Surgery, Vol. 20, No. 3, 1988, pp. 256-260. doi:10.1097/00000637-198803000-00013

[57] W. J. Holtje, "Successful Replantation of an Amputated Upper Lip,” Plastic \& Reconstructive Surgery, Vol. 73, No. 4, 1984, pp. 644-670. doi:10.1097/00006534-198404000-00027

[58] A. Okumus, S. Vasfi Kuvat and F. Kabakas, "Successful Replantation of an Amputated Nose after Occupational Injury,” Journal of Craniofacial Surgery, Vol. 21, No. 1, 2010, pp. 289-290. doi:10.1097/SCS.0b013e3181c67dc0

[59] S. S. Wong and M. L. Wang, "Successful Replantation of an Bitten-Off Lower Lip: Case Report," Journal of Trauma-Injury Infection \& Critical Care, Vol. 47, No. 4, 1999, pp. 602-604. doi:10.1097/00005373-199909000-00037

[60] R. L. Walton, E. K. Beahm, R. E. Brown, et al., "Microsurgical Replantation of the Lip: A Multi-Institutional Experience,” Plastic \& Reconstructive Surgery, Vol. 102, No. 2, 1998, pp. 358-368. doi:10.1097/00006534-199808000-00009

[61] A. Sánchez-Olaso, "Replantation of an Amputated Nasal Tip with Open Venous Drainage,” Microsurgery, Vol. 14, No. 6, 1993, pp. 380-383. doi:10.1002/micr.1920140605

[62] D. C. Hammond, C. L. Bouwense, W. T. Hankins, G. S. Maxwell-Davis, J. Furdyna and P. A. Capipraro, "Microsurgical Replantation of the Amputated Nose,” Plastic \& Reconstructive Surgery, Vol. 105, No. 6, 2000, pp. 21332137. doi:10.1097/00006534-200005000-00033

[63] F. Schonauer, J. W. Blair, D. M. Moloney, T. C. Teo and M. A. Pickford, "Three Cases of Successful Microvascular Replantation after Bite Avulsion Injury,” Scandinavian Journal of Plastic \& Reconstructive Surgery \& Hand Surgery, Vol. 38, No. 3, 2004, pp. 177-182. doi:10.1080/02844310310016269

[64] G. M. Kind, G. M. Buncke, O. J. Placik, D. A. Jansen, T. 
D’Amore and H. J. Buncke Jr., “Total Ear Replantation,” Plastic \& Reconstructive Surgery, Vol. 99, No. 7, 1997, pp. 1858-1867. doi:10.1097/00006534-199706000-00008

[65] D. Erdmann, A. D. Bruno, K. E. Follmar, T. H. Stokes, D. L. Gonyon and J. R. Marcus, "The Helical Arcade: Anatomic Basis for Survival in Near-Total Ear Avulsion," The Journal of Craniofacial Surgery, Vol. 20, No. 1, 2009, pp. 245-248. doi:10.1097/SCS.0b013e318184343a

[66] C. R. Crawford and R. C. Hagerty, "Survival of an Upper Lip Aesthetic Complex Using Arterial Reanastomosis Only,” Annals of Plastic Surgery, Vol. 27, No. 1, 1991, pp. 77-79. doi:10.1097/00000637-199107000-00013

[67] A. Kayikcioglu, S. Karamursel and A. Kecik, "Replantation of Nearly Total Nose Amputation without Venous Anastomosis," Plastic \& Reconstructive Surgery, Vol. 108, No. 3, 2001, pp. 702-704. doi:10.1097/00006534-200109010-00015

[68] J. M. Yao, S. Yan, J. H. Xu, J. B. Li and P. Ye, "Replantation of Amputated Nose by Microvascular Anastomosis,” Plastic \& Reconstructive Surgery, Vol. 102, No. 1, 1998, pp. 171-173. doi:10.1097/00006534-199807000-00027

[69] X. Q. Shen, C. Wang, J. H. Xu and S. C. Wu, "Successful Microsurgical Replantation of a Child's Completely Amputated Ear," Journal of Plastic, Reconstructive \& Aesthetic Surgery, Vol. 61, No. 12, 2008, pp. e19-e22. doi:10.1016/j.bjps.2007.07.010

[70] P. C. Cavadas, "Supramicrosurgical Ear Replantation: Case Report," Journal of Reconstructive Microsurgery, Vol. 18, No. 5, 2002, pp. 393-395. doi:10.1055/s-2002-33022

[71] T. de Chalain and G. Jones, "Replantation of the Avulsed Pinna: 100 Percent Survival with a Single Arterial Anastomosis and Substitution of Leeches for a Venous Anastomosis,” Plastic \& Reconstructive Surgery, Vol. 95, No. 7, 1995, pp. 1275-1279. doi:10.1097/00006534-199506000-00021

[72] M. J. Concannon and C. L. Puckett, "Microsurgical Replantation of an Ear in a Child without Venous Repair," Plastic \& Reconstructive Surgery, Vol. 102, No. 6, 1998, pp. 2088-2093.

[73] R. K. Nath, B. A. Kraemer and A. Azizzadeh, "Complete Ear Replantation without Venous Anastomosis," Microsurgery, Vol. 18, No. 4, 1998, pp. 282-285. doi:10.1002/(SICI)1098-2752(1998)18:4<282::AID-MIC R13>3.3.CO;2-V

[74] B. H. Cho and H. B. Ahn, "Microsurgical Replantation of a Partial Ear, with Leech Therapy," Annals of Plastic Surgery, Vol. 43, No. 4, 1999, pp. 427-429. doi:10.1097/00000637-199910000-00014

[75] K. S. Kim, E. S. Kim, J. H. Hwang and S. Y. Lee, "Microsurgical Replantation of a Partial Helix of the Ear," Microsurgery, Vol. 29, No. 7, 2009, pp. 548-551. doi:10.1002/micr.20643

[76] A. J. Hussey and J. I. Kelly, "Microsurgical Replantation of an Ear with No Venous Repair,” Scandinavian Journal of Plastic \& Reconstructive Surgery \& Hand Surgery, Vol. 44, No. 1, 2010, pp. 64-65.
[77] J. Katsaros, E. Tan and R. Sheen, "Microvascular Ear Replantation,” British Journal of Plastic Surgery, Vol. 41, No. 5, 1988, pp. 496-499. doi:10.1016/0007-1226(88)90006-9

[78] J. Juri, A. Irigaray, C. Juri, D. Grilli, C. M. Blanco and G. D. Vazquez, "Ear Replantation," Plastic \& Reconstructive Surgery, Vol. 80, No. 3, 1987, pp. 431-435. doi:10.1097/00006534-198709000-00016

[79] I. M. Turpin, "Microsurgical Replantation of the External Ear,” Clinics in Plastic Surgery, Vol. 17, No. 2, 1990, pp. 397-404.

[80] J. K. Chun, T. P. Sterry, S. L. Margoles and L. Silver, "Salvage of Ear Replantation Using the Temporoparietal Fascia Flap,” Annals of Plastic Surgery, Vol. 44, No. 4, 2000, pp. 435-439. doi:10.1097/00000637-200044040-00015

[81] D. G. Pennington and T. E. Pennington, "30-Year Follow-Up of the First Successfully Replanted Ear,” Plastic and Reconstructive Surgery, Vol. 126, No. 1, 2010, pp. e21-e23. doi:10.1097/PRS.0b013e3181dab397

[82] R. K. Daniel and G. I. Taylor, "Distant Transfer of an Island Flap by Microvascular Anastomoses. A Clinical Technique," Plastic \& Reconstructive Surgery, Vol. 52, No. 2, 1973, pp. 111-117. doi:10.1097/00006534-197308000-00001

[83] K. Harii, K. Ohmori and J. Sekiguchi, "The Free Musculocutaneous Flap,” Plastic \& Reconstructive Surgery, Vol. 57, No. 3, 1976, pp. 294-303. doi:10.1097/00006534-197603000-00003

[84] J. S. Watson, R. D. Craig and C. I. Orton, "The Free Latissimus Dorsi Myocutaneous Flap,” Plastic \& Reconstructive Surgery, Vol. 64, No. 3, 1979, pp. 299-305. doi:10.1097/00006534-197909000-00002

[85] Y. G. Song, G. Z. Chen and Y. L. Song, "The Free Thigh Flap: A New Free Flap Concept Based on the Septocutaneous Artery,” British Journal of Plastic Surgery, Vol. 37, No. 2, 1984, pp. 149-159. doi:10.1016/0007-1226(84)90002-X

[86] F. C. Wei, V. Jain, N. Celik, H. C. Chen, D. C. Chuang and C. H. Lin, "Have We Found an Ideal Soft-Tissue Flap? An Experience with 672 Anterolateral Thigh Flaps,” Plastic \& Reconstructive Surgery, Vol. 109, No. 7, 2002, pp. 2219-2226. doi:10.1097/00006534-200206000-00007

[87] N. Celik, F. C. Wei, C. H. Lin, et al., "Technique and Strategy in Anterolateral Thigh Perforator Flap Surgery, Based on an Analysis of 15 Complete and Partial Failures in 439 Cases," Plastic \& Reconstructive Surgery, Vol. 109, No. 7, 2002, pp. 2211-2216. doi:10.1097/00006534-200206000-00005

[88] Y. R. Kuo, S. F. Jeng, F. M. Kuo, Y. T. Liu and P. W. Lai, "Versatility of the Free Anterolateral Thigh Flap for Reconstruction of Soft-Tissue Defects: Review of 140 Cases,” Annals of Plastic Surgery, Vol. 48, No. 2, 2002, pp. 161-166. doi:10.1097/00000637-200202000-00008

[89] I. Koshima, H. Fukuda, H Yamamoto, T. Moriguchi, S. Soeda and S. Ohta, "Free Anterolateral Thigh Flaps for Reconstruction of Head and Neck Defects,” Plastic \& Reconstructive Surgery, Vol. 92, No. 3, 1993, pp. 421- 
428. doi:10.1097/00006534-199309000-00005

[90] J. S. Chana and F. C. Wei, “A Review of the Advantages of the Anterolateral Thigh Flap in Head and Neck Reconstruction,” British Journal of Plastic Surgery, Vol. 57, No. 7, 2004, pp. 603-609. doi:10.1016/j.bjps.2004.05.032

[91] N. Kimura and K. Satoh, "Consideration of a Thin Flap as an Entity and Clinical Applications of the Thin Anterolateral Thigh Flap,“ Plastic \& Reconstructive Surgery, Vol. 97, No. 5, 1996, pp. 985-992. doi:10.1097/00006534-199604001-00016

[92] C. H. Lin, F. C. Wei, Y. T. Lin, J. T. Yeh, J. Rodriguez Ede and C. T. Chen, "Lateral Circumflex Femoral Artery System: Warehouse for Functional Composite Free-Tissue Reconstruction of the Lower Leg," Journal of Trauma, Vol. 60, No. 5, 2006, pp. 1032-1036. doi:10.1097/01.ta.0000218248.22811.70

[93] I. Koshima, H. Yamamoto, T. Moriguchi and Y. Orita, "Extended Anterior Thigh Flaps for Repair of Massive Cervical Defects Involving Pharyngoesophagus and Skin: An Introduction to the 'Mosaic' Flap Principle," Annals of Plastic Surgery, Vol. 32, No. 3, 1994, pp. 321-327.

[94] I. Koshima, S. Hosoda, K. Inagawa, K. Urushibara and T. Moriguchi, "Free Combined Anterolateral Thigh Flap and Vascularized Fibula for Wide, through-and-through Oromandibular Defects," Journal of Reconstructive Microsurgery, Vol. 14, No. 8, 1998, pp. 529-534. doi:10.1055/s-2008-1040770

[95] G. G. Hallock, "Simultaneous Transposition of Anterior Thigh Muscle and Fascia Flaps: An Introduction to the Chimera Flap Principle,” Annals of Plastic Surgery, Vol. 27, No. 2, 1991, pp. 126-131. doi:10.1097/00000637-199108000-00006

[96] I. Koshima, H. Yamamoto, M. Hosoda, T. Moriguchi, Y. Orita and H. Nagayama, "Free Combined Composite Flaps Using the Lateral Circumflex Femoral System for Repair of Massive Defects of the Head and Neck Regions: An Introduction to the Chimeric Flap Principle," Plastic \& Reconstructive Surgery, Vol. 92, No. 3, 1993, pp. 411420. doi:10.1097/00006534-199309000-00004

[97] J. M. Rodriguez-Vegas, P. A. Angel and P. R. Manuela, "Refining the Anterolateral Thigh Free Flap in Complex Orbitomaxillary Reconstructions,” Plastic \& Reconstructive Surgery, Vol. 121, No. 2, 2008, pp. 481-486. doi:10.1097/01.prs.0000299182.78690.f8

[98] N. Adler, A. H. Dorafshar, J. P. Agarwal and L. J. Gottlieb, "Harvesting the Lateral Femoral Circumflex Chimera Free Flap: Guidelines for Elevation,” Plastic \& Reconstructive Surgery, Vol. 123, No. 3, 2009, pp. 918-925. doi:10.1097/PRS.0b013e318199f51c

[99] J. P. Hong, H. W. Shin, J. J. Kim, F. C. Wei and Y. K. Chung, "The Use of Anterolateral Thigh Perforator Flaps in Chronic Osteomyelitis of the Lower Extremity," Plastic \& Reconstructive Surgery, Vol. 115, No. 1, 2005, pp. 142-147.

[100] I. Koshima, "Free Anterolateral Thigh Flap for Reconstruction of Head and Neck Defects following Cancer Ablation,” Plastic \& Reconstructive Surgery, Vol. 105, No. 7, 2000, pp. 2358-2360. doi:10.1097/00006534-200006000-00007
[101]H. C. Chen and Y. B. Tang, "Anterolateral Thigh Flap: An Ideal Soft Tissue Flap," Clinics in Plastic Surgery, Vol. 30, No. 3, 2003, pp. 383-401. doi:10.1016/S0094-1298(03)00040-3

[102] F. Demirkan, H. C. Chen, F. C. Wei, et al., “The Versatile Anterolateral Thigh Flap: A Musculocutaneous Flap in Disguise in Head and Neck Reconstruction," British Journal of Plastic Surgery, Vol. 53, No. 1, 2000, pp. 30 36. doi:10.1054/bjps.1999.3250

[103] A. Spyropoulou and S. F. Jeng, "Microsurgical Coverage Reconstruction in Upper and Lower Extremities," Seminars in Plastic Surgery, Vol. 24, No. 1, 2010, pp. 34-43. doi:10.1055/s-0030-1253244

[104] S. J. Shieh, H. Y. Chiu, J. C. Yu, S. C. Pan, S. T. Tsai, and C. L. Shen, "Free Anterolateral Thigh Flap for Reconstruction of Head and Neck Defects following Cancer Ablation," Plastic \& Reconstructive Surgery, Vol. 105, No. 7, 2000, pp. 2349-2357. doi:10.1097/00006534-200006000-00006

[105] J. S. Chana and F. C. Wei, “Anterolateral Thigh Flap in Head and Neck Reconstruction,” British Journal of Plastic Surgery, Vol. 57, No. 7, 2004, pp. 603-609. doi:10.1016/j.bjps.2004.05.032

[106] N. Celik, F. C. Wei, C. H. Lin, et al., "Technique and Strategy in Anterolateral Thigh Perforator Flap Surgery, Based on an Analysis of 15 Complete and Partial Failures in 439 Cases," Plastic \& Reconstructive Surgery, Vol. 109, No. 7, 2002, pp. 2211-2216.

[107] N. Celik and F. C. Wei, “Technical Tips in Perforator Flap Harvest,” Clinics in Plastic Surgery, Vol. 30, No. 3, 2003, pp. 469-472. doi:10.1016/S0094-1298(03)00042-7

[108] R. Boca, Y. R. Kuo, C. H. Hsieh, E. Y. Huang and S. F. Jeng, "A Reliable Parameter for Primary Closure of the Free Anterolateral Thigh Flap Donor Site,” Plastic \& Reconstructive Surgery, Vol. 126, No. 5, 2010, pp. 15581562. doi:10.1097/PRS.0b013e3181ef8cb7

[109] S. Yildirim, K. Gideroglu and T. Akoz, “Anterolateral Thigh Flap: Ideal Free Flap Choice for Lower Extremity Soft-Tissue Reconstruction," Journal of Reconstructive Microsurgery, Vol. 19, No. 4, 2003, pp. 225-233. doi:10.1055/s-2003-40578

[110] Y. R. Kuo, S. F. Jeng, M. H. Kuo, et al., "Free Anterolateral Thigh Flap for Extremity Reconstruction: Clinical Experience and Functional Assessment of Donor Site," Plastic \& Reconstructive Surgery, Vol. 107, No. 7, 2001, pp. 1766-1771. doi:10.1097/00006534-200106000-00019

[111] Y. Kimata, K. Uchiyama, S. Ebihara, et al., “Anterolateral Thigh Flap Donor-Site Complications and Morbidity,” Plastic \& Reconstructive Surgery, Vol. 106, No. 3, 2000, pp. 584-589. doi:10.1097/00006534-200009030-00009

[112] I. Koshima, M. Fujitsu, S. Ushio, N. Sugiyama and S. Yamashita, "Flow-through Anterior Thigh Flaps with a Short Pedicle for Reconstruction of Lower Leg and Foot Defects,” Plastic \& Reconstructive Surgery, Vol. 115, No. 1, 2005, pp. 155-162.

[113] B. Nakayama, I. Hyodo, Y. Hasegawa, et al., "Role of the Anterolateral Thigh Flap in Head and Neck Reconstruction: Advantages of Moderate Skin and Subcutaneous 
Thickness,” Journal of Reconstructive Microsurgery, Vol. 18, No. 3, 2002, pp. 141-146. doi:10.1055/s-2002-28463

[114] P. Yu, "Characteristics of the Anterolateral Thigh Fap in a Western Population and Its Application in Head and Neck Reconstruction,” Head and Neck, Vol. 26, No. 9, 2004, pp. 759-765. doi:10.1002/hed.20050

[115] G. L .Ross, R. Dunn, J. Kirkpatrick, et al., "To Thin or Not to Thin: The Use of the Anterolateral Thigh Flap in the Reconstruction of Intraoral Defects," British Journal of Plastic Surgery, Vol. 56, No. 4, 2003, pp. 409-413. doi:10.1016/S0007-1226(03)00126-7

[116] S. E. Sharabi, D. A. Hatef, J. C. Koshy, A. Jain, P. D. Cole and L. H. Hollier Jr., "Is Primary Thinning of the Anterolateral Thigh Flap Recommended?” Annals of Plastic Surgery, Vol. 65, No. 6, 2010, pp. 555-559. doi:10.1097/SAP.0b013e3181cbfebc

[117] W. Baird and F. Nahai, "The Use of Lipoplasty in Contouring and Debulking of Flaps," Clinics in Plastic Surgery, Vol. 16, No. 2, 1989, pp. 395-399.

[118] A. Mowlavi and R. E. Brown, "Suction Lipectomy during Flap Reconstruction Provides Immediate and Safe Debulking of the Skin Island," Annals of Plastic Surgery, Vol. 51, No. 2, 2003, pp. 189-193. doi:10.1097/01.SAP.0000054243.97398.1A

[119] C. H. Hsieh, J. C. Yang, C. C. Chen, Y. R. Kuo and S. F. Jeng, "Alternative Reconstructive Choices for Anterolateral Thigh Flap Dissection in Cases in which No Sizable Skin Perforator Is Available,“ Head \& Neck, Vol. 31, No. 5, 2009, pp. 571-575. doi:10.1002/hed.20995

[120] G. I. Taylor and J. H. Palmer, "The Vascular Territories (Angiosomes) of the Body: Experimental Study and Clinical Applications,” British Journal of Plastic Surgery, Vol. 40, No. 2, 1987, pp. 113-141. doi:10.1016/0007-1226(87)90185-8

[121] G. I. Taylor, M. Doyle and G. McCarten, “The Doppler Probe for Planning Flaps: Anatomical Study and Clinical Applications,” British Journal of Plastic Surgery, Vol. 43, No. 1, 1990, pp. 1-16. doi:10.1016/0007-1226(90)90039-3

[122] F. C. Wei, V. Jain, S. Suominen and H. C. Chen, "Confusion among Perforator Flaps: What Is a True Perforator Flap?” Plastic \& Reconstructive Surgery, Vol. 107, No. 3, 2001, pp. 874-876. doi:10.1097/00006534-200103000-00037

[123] P. N. Blondeel, S. F. Morris, G. G. Hallock and P. C. Neligan, "Reconstructive Surgery: Anatomy, Technique and Clinical Applications,” Quality Medical Publishing, St Louis, 2006.

[124] S. Mardini and F. C. Wei, "Flaps and Reconstructive Surgery,” Elsevier, New York, 2009.

[125] F. C. Wei and S. Mardini, "Free-Style Free Flaps,” Plastic \& Reconstructive Surgery, Vol. 114, No. 4, 2004, pp. 910-916. doi:10.1097/01.PRS.0000133171.65075.81

[126] F. G. Bravo and H. P. Schwarze, "Free-Style Local Perforator Flaps: Concept and Classification System,” Journal of Plastic, Reconstructive \& Aesthetic Surgery, Vol. 62, No. 5, 2009, pp. 602-608.

[127] C. C. Chang, C. H. Wong and F. C. Wei, "Free-Style Free
Flap,” Injury, Vol. 39, Suppl. 3, 2008, pp. S57-S61. doi:10.1016/j.injury.2008.05.020

[128] C. Wallace, H. K. Kao, S. F. Jeng and F. C. Wei, "Free-Style Flaps: A Further Step Forward for Perforator Flap Surgery," Plastic \& Reconstructive Surgery, Vol. 124, Suppl. 6, 2009, pp. e419-e426. doi:10.1097/PRS.0b013e3181bcf189

[129] S. F. Morris, P. C. Neligan and G. I. Taylor, "Free Style Local Perforator Flaps,” In: P. N. Blondeel, S. F. Morris, G. G. Hallock and P. C. Neligan, Eds., Perforator Flaps: Anatomy, Technique and Clinical Applications, Quality Medical Publishing, St. Louis, 2006, pp. 948-960.

[130] J. P. Meningaud, M. Hivelin, M. D. Benjoar, G. Toure, O. Hermeziu and L. Lantieri, "The Procurement of Allotransplants for Ballistic Trauma: A Peclinical Study and a Report of Two Clinical Cases,” Plastic \& Reconstructive Surgery, Vol. 127, No. 5, 2011, pp. 1892-1900. doi:10.1097/PRS.0b013e31820e915a

[131] T. Gomez-Cia, D. Sicilia-Castro, P. Infante-Cossio, et al., "Second Human Facial Allotransplantation to Restore a Severe Defect Following Radical Resection of Bilateral Massive Plexiform Neurofibromas," Plastic \& Reconstructive Surgery, Vol. 127, No. 2, 2011, pp. 995-996. doi:10.1097/PRS.0b013e318200b00b

[132] B. Pomahac, P. Aflaki, A. Chandraker and J. J. Pribaz, "Facial Transplantation and Immunosuppressed Patients: A New Frontier in Reconstructive Surgery,” Transplantation, Vol. 85, No. 12, 2008, pp. 1693-1697. doi:10.1097/TP.0b013e318176b29e

[133] C. R. Gordon, “A Four-Type Classification System for Microvascular Reconstruction of Oncologic Midface Defects: But What about Maxillofacial Allotransplantation?” Plastic \& Reconstructive Surgery, Vol. 128, No.1, 2011, pp. 323-325. doi:10.1097/PRS.0b013e3182174373

[134] C. R. Gordon, M. Siemionow, F. Papay, et al., "The World's Experience with Facial Transplantation: What Have We Learned Thus Far?” Annals of Plastic Surgery, Vol. 63, No. 5, 2009, pp. 572-578. doi:10.1097/SAP.0b013e3181ba5245

[135] B. Devauchelle, L. Badet, B. Lengelé, et al., "First Human Face Allograft: Early Report,” Lancet, Vol. 368, No. 9531, 2006, pp. 203-209. doi:10.1016/S0140-6736(06)68935-6

[136] J. M. Dubernard, B. Lengelé, E. Morelon, et al., "Outcomes 18 Months after the First Human Partial Face Transplantation,” The New England Journal of Medicine, Vol. 357, No. 24, 2007, pp. 2451-2460. doi:10.1056/NEJMoa072828

[137] S. Guo, Y. Han, X. Zhang, et al., "Human Facial Allotransplantation: A 2-Year Follow-Up Study,” Lancet, Vol. 372, No. 9639, 2008, pp. 631-638. doi:10.1016/S0140-6736(08)61276-3

[138] L. Lantieri, J. P. Meningaud, P. Grimbert, et al., "Repair of the Lower and Middle Parts of the Face by Composite Tissue Allotransplantation in a Patient with Massive Plexiform Neurofibroma: A 1-Year Follow-Up Study,” Lancet, Vol. 372, No. 9639, 2008, pp. 639-645. doi:10.1016/S0140-6736(08)61277-5

[139] M. Siemionow, F. Papay, D. Alam, et al., "Near-Total 
Human Face Transplantation for a Severely Disfigured Patient in the USA," Lancet, Vol. 374, No. 9685, 2009, pp. 203-209. doi:10.1016/S0140-6736(09)61155-7

[140] B. Pomahac, B. Lengele, E. B. Ridgway, et al., "Vascular Considerations in Composite Midfacial Allotransplantation,” Plastic \& Reconstructive Surgery, Vol. 125, No. 2, 2010, pp. 517-522. doi:10.1097/PRS.0b013e3181c82e6f

[141] J. Bueno, J. P. Barret, J. Serracanta, et al., "Logistics and Strategy of Multiorgan Procurement Involving Total Face Allograft," American Journal of Transplantation, Vol. 11, No. 5, 2011, pp. 1091-1017. doi:10.1111/j.1600-6143.2011.03489.x

[142] D. S. Alam, F. Papay, R. Djohan, et al., "The Technical and Anatomical Aspects of the World's First Near-Total Human Face and Maxilla Transplant," Archives in Facial Plastic Surgery, Vol. 11, No. 6, 2009, pp. 369-377. doi:10.1001/archfacial.2009.80

[143] M. Siemionow and C. R. Gordon, "Overview of Guidelines for Establishing a Face Transplant Program: A Work in Progress," American Journal of Transplantation, Vol. 10, No. 5, 2010, pp. 1290-1296. doi:10.1111/j.1600-6143.2010.03096.x
[144] H. G. Hui-Chou, A. J. Nam and E. D. Rodriguez, "Clinical Facial Composite Tissue Allotransplantation: A Review of the First Four Global Experiences and Future Implications,” Plastic \& Reconstructive Surgery, Vol. 125, No. 2, 2010, pp. 538-546. doi:10.1097/PRS.0b013e3181c722a8

[145] M. Siemionow, R. Djohan and F. Papay, “Cost Analysis of Conventional Facial Reconstruction Procedures Followed by Face Transplantation," American Journal of Transplantation, Vol. 11, No. 2, 2011, pp. 379-385.

[146] A. J. Alexander, D. S. Alam, P. J. Gullane, B. G. Lengelé and P. A. Adamson, "Arguing the Ethics of Facial Transplantation,” Archives of Facial Plastic Surgery, Vol. 12, No. 1, 2010, pp. 60-63. doi:10.1001/archfacial.2009.106

[147] K. L. Coffman, C. Gordon and M. Siemionow, "Psychological Outcomes with Face Transplantation: Overview and Case Report," Current Opinion in Organ Transplantation, Vol. 15, No. 2, 2010, pp. 236-240.

[148] C. Paradis, M. Siemionow, F. Papay, et al., "Ethical Considerations in the First American Face Transplant," Plastic \& Reconstructive Surgery, Vol. 126, No. 3, 2010, pp. 896-901. doi:10.1097/PRS.0b013e3181e3b63d 